\title{
Reinsurance and Solvency Capital: Mitigating Insurance Companies' Ruin Probability
}

\author{
Resseguro e Capital de Solvência: Atenuantes da Probabilidade de Ruína \\ de Seguradoras
}

\section{ABSTRACT}

Context: insurance companies are important to society, since they guarantee financial protection to individuals from property losses, in addition to fostering the capital market through the allocation of guarantee assets. Thus, it is essential to evaluate the instruments that guarantee their long-term financial solvency. Among them are the adoption of reinsurance treaties, the sizing of the solvency capital, and the actuarial modeling of risk processes, which allow the measurement of the ruin probability. Objective: estimate the ruin probability in risk processes with the adoption of reinsurance contracts (quota share and excess of loss), compared to scenarios without such treaties. Methods: the Cramér-Lundberg process was simulated using the Monte Carlo method, adjusting several probabilistic distributions to the severity of the compound Poisson process, which is calibrated with a set of 3,917,863 real microdata, from 30 insurance lines of business. Results: it was found that, although each branch presents particularities in the claim severity, the correct choice of reinsurance (proportional or not) implies the reduction of the ruin probability for a fixed solvency capital. Conclusion: the appropriate choice of the reinsurance contract, especially when there is evidence of high kurtosis in the claim values, intensifies the exponential decline in the relationship between the solvency capital and the ruin probability.

Keywords: risk processes; reinsurance; solvency capital; ruin probability.
Jorge Wilson Euphasio Junior ${ }^{1} \bullet$ João Vinícius França Carvalho*1 ब

\footnotetext{
* Corresponding Author.

1. Universidade de São Paulo, Faculdade de Economia, Administração, Contabilidade e Atuária, São Paulo, SP, Brazil.
}

Cite as: Euphasio Junior, J. W., \& Carvalho, J. V. F. (2022). Reinsurance and solvency capital: Mitigating insurance companies' ruin probability. Revista de Administração Contemporânea, 26(1), e200191. https://doi.org/10.1590/1982-7849rac2022200191.en

\section{RESUMO}

Contexto: seguradoras são importantes à sociedade, uma vez que garantem proteção financeira aos indivíduos contra perdas patrimoniais, além de fomentarem o mercado de capitais por meio da alocação de ativos garantidores. Assim, é fundamental avaliar os instrumentos que garantam sua solvência financeira de longo prazo. Dentre eles estáo a adoçáo de tratados de resseguro, alocaçáo de capital de solvência e modelagem atuarial dos processos de risco. Objetivo: estimar a probabilidade de ruína em processos de risco com a adoção de contratos de resseguro (quota-parte e excesso de danos), comparativamente a cenários sem tais tratados. Métodos: simulou-se o processo de CramérLundberg via método de Monte Carlo, ajustando diversas distribuiçóes probabilísticas à severidade do processo de Poisson composto, calibrando um conjunto de 3.917.863 microdados reais, segregados em 30 ramos securitários. Resultados: ainda que cada ramo apresente particularidades na severidade do sinistro, a correta escolha de resseguro (proporcional ou náo) implica a redução da probabilidade de ruína para um capital de solvência fixo. Conclusáo: a escolha adequada do contrato de resseguro, especialmente quando há evidências de elevada curtose nos valores de sinistros, intensifica o decaimento exponencial da relação entre o capital de solvência e a probabilidade de ruína.

Palavras-chave: processos de risco; resseguro; capital de solvência; probabilidade de ruína.
JEL Code: G22, C15, C63.

Editor-in-chief: Wesley Mendes-Da-Silva (Fundação Getulio Vargas, EAESP, Brasil) (1) Reviewers: Roberto Cazzari (Universidade Federal de São Paulo, Brasil) (I) Elizabeth Borelli (Pontifícia Universidade Católica de São Paulo, Brasil) Peer Review Report: The Peer Review Report is available at this external URL.

Received: May 22, 2020 Last version received: August 12, 2020 Accepted: August 14, 2020 


\section{INTRODUCTION}

The insurance market is becoming increasingly important to the Brazilian economy, as its share of Gross Domestic Product (GDP) went from 2.59\% in 2003 to $3.82 \%$ in 2016 (BRL 239.4 billion), according to an official report from the Superintendence of Private Insurance - Susep (Superintendência de Seguros Privados [SUSEP], 2018). During this period, the insurers' annual revenues grew at the average annual real rate of $16.60 \%$, more than the Brazilian economy, which increased at the average annual real rate of $4.14 \%$.

The insurance contract provides financial reimbursement from adverse events that, in case of materialization, may result in property losses for a company with legitimate and common interests. Thus, from the moment that entities recognize an insolvency position, insured individuals and beneficiaries will not receive the expected coverages in case of claims, generating a negative externality that goes beyond the consequences inherent at companies operation. In addition, insurance companies and pension funds are large institutional investors, and a relevant systemic risk can be created in case of insolvency.

In this context, the ruin probability calculation becomes essential, since it provides a measure of the premium deficiency exposure size, as well as the possibility of incurring bankruptcy in future scenarios (Baumgartner \& Gatto, 2010). The probability estimation is also fundamental to scale the amounts required in the present to maintain a level of future solvency. For this case, the Solvency II directive, analogous to Basel III for banks, establishes the obligation to calculate a risk-based capital (RBC, or solvency capital, SC), in addition to a regulatory base capital (BC). These reserves aim to provide for the insurers capacity to fulfill the commitments assumed when a serious adverse operational shock occurs, establishing a capital insufficiency probability of only $0.5 \%$, which would ensure that the ruin would not occur more than once every 200 years, on average (Moro \& Krvavych, 2017).

In order to ensure convergence to the Solvency II guidelines, the local regulator, through CNSP Resolution No. 321/2015, disposes about the indispensability of booking a minimum required capital (MRC). The MRC is the total risk capital that an insurance company, private pension fund, investment firm, or local reinsurer must maintain at any time aiming at its businesses continuity, being equal to the maximum between $\mathrm{BC}$ (defined by law, depending on the company legal nature) and RBC (a variable amount depending on the inherent risks to its operation).
This RBC, still according to the law, must be segregated in order to reflect the different types of risks to which a company is exposed, such as: capital based on (a) underwriting risk (for each line of business that the entity operates), (b) credit risk (which reflects potential exposures to reinsurers, coinsurers, and other counterparties default), (c) operational risk (which measures the possibility of losses from failure, internal processes deficiency or inadequacy, people and systems, or even resulting from fraud or external events, including legal risk and excluding risks from strategic decisions and the institution's reputation), and (d) market risk (losses from financial market fluctuations, which cause substantial changes in the assets' and liabilities' economic valuations).

In the end, all these calculated capital are connected through a quadratic form and, considering a dependency structure stipulated by the regulator, combined in a single measure (the MRC), which is allocated as adjusted equity. Therefore, the correct capital reserves assessment derives from a consistent probability estimate of an insurer going bankrupt.

In this paper, underwriting risks are the main interest of analysis, which are idiosyncratic in the insurance industry. But in addition to the booking of capital based on underwriting risk, reinsurance is another option that the insurer has to reduce its operation volatility, causing changes in the reserves level as a direct consequence of its adoption. Specifically with regard to mitigating the claims variability, reinsurance acts as the main tool in reducing managerial risk measures, including the ruin probability. The appropriate choice of the reinsurance treaty implies an increase on the adjustment coefficient, a representative measure of the mismatch between premiums and claims (Bowers, Gerber, Hickman, Jones, \& Nesbitt, 1997). Therefore, the company will be less exposed to ruin the more careful the contract choice is, since higher this coefficient will be.

This paper has as main objective to estimate the ruin probability of an insurance entity when taking into account mechanisms to limit contractual guarantees, comparing to scenarios without such limitations. As a secondary objective, and derived directly from the first, to measure the solvency capital associated with underwriting risks. Ruin probability is defined as the expected frequency of times that the insurer would have declared bankruptcy in future scenarios. Ruin is understood as the state that arises from a capital reserve being fully consumed after income and expenses management operations have been carried out.

Actual databases provided by an insurer (transformed to maintain its confidentiality) are used in 
order to numerically evaluate the results obtained. Based on this information, risk processes will be simulated, from which the respective ruin probabilities will be calculated. Then, a comparison with the reinsurance presence will be made, in which proportional and excess of loss contracts will be considered, in order to measure not only the impacts of adopting this tool on the ruin probability, but also the effects of choosing different types of treaties, considering the different portfolios dynamics.

\section{THEORETICAL GROUNDWORK AND EMPIRICAL LITERATURE}

\section{Reinsurance treaties and its structure}

In line with Bowers, Gerber, Hickman, Jones and Nesbitt (1997), the reinsurance treaty is a contract agreed by the insurer (cedent) with a reinsurer, in order to transfer the financial coverage burden of uncertain events (extreme or not). One of the reinsurance functions is to protect the insurer's balance sheet against the following scenarios: (a) claims accumulation from many policies affected by the same event; (b) severe claims; or (c) when the aggregate loss of a portfolio goes well beyond expectations. All these unwanted situations, in the absence of reinsurance protection, can cause the insurer to go bankrupt, which is the solely responsible for the policyholder payment.

Thus, it is through the adoption of the reinsurance treaty that the cedent covers extreme claims, allowing the company to increase its gross subscription beyond the retention level defined by the current guidelines of the regulator, however, respecting them from the net subscription perspective. This retention limit (RL), defined by the insurer, is a function of the adjusted equity and imposes a restriction on the operational capacity in the new insurance contracts underwriting. Therefore, in risk processes, the type of reinsurance contract adopted directly impacts the ruin probability estimation, as its structure will reflect on both the claims expectation and variability.

According to Deelstra and Plantin (2014), reinsurance treaties can be classified as proportional reinsurance (among which stand out the quota share and surplus) or non-proportional (the main ones are excess of loss per risk - XL/R - excess of loss per event $\mathrm{XL} / \mathrm{E}$ - , catastrophe excess of loss, and stop-loss). In this paper, only one type of each category will be analyzed: quota share and excess of loss per risk. Let $X$ be a random variable that denotes the severity associated with a loss. Thus, a reinsurance contract $h$ is a transformation into the original random variable:
1) $h(X)=\alpha X, 0 \leq \alpha \leq 1$ (quota share); 2) $h_{d}(X)=X^{\wedge} d=\min \{X ; d\}$ (excess of loss per risk).

Equation (1) presents the mathematical formulation for the reinsurance contracts considered in the simulations, which have different interpretations, objectively, depending on their characteristics. In the first case, $\alpha$ represents the retention rate applied on the claim amount, which can be obtained by dividing the retained premium by the total premium. In other words, for proportional contracts, the premiums and claims proportions divided between the insurer and reinsurer are identical, regardless of the claim severity. As advantages, this treaty presents easy implementation and management, and reduction on moral hazard since the insurer and reinsurer have congruence of interests.

The second does not satisfy the same rate of premiums and claims ceded, leaving one party with a greater share of the insured risk (generally, the reinsurer). The reinsurer intervenes only if the claims amount is higher than an established priority $(d)$. The priority defines the insurer's exclusive responsibility, regardless of the amount in excess of $d$. In a nutshell, for a nonproportional contract, the premiums' fraction transferred to the reinsurer is not necessarily identical to the ceded claim's coverage fraction.

In practice, this limit is divided into layers (priorities), which consist of different retention (fixed) levels, facilitating the contracts pricing, as each reinsurer can choose the degree of its exposure in each company. The higher layers' premiums are more costly, since these levels configure the insurers' distributions tails, and their payment occurs only when an exceedingly high priority is crossed. The reinsurance operational design allows insurers to achieve a volatility reduction on their respective portfolios (Bowers et al., 1997). Since both the mean and variance decrease, it is possible to conclude that, for the same ruin probability, when there is a reinsurance, less initial reserve is necessary.

Bowers et al. (1997) show (Theorem 14.5.1) that the excess of loss reinsurance (XL/R), under certain conditions, is always optimal when compared to proportional reinsurance, in the way of adjustment coefficient maximizing, thus decreasing ruin probability. What the theorem does not reveal is the magnitude of this reduction, mainly because the adjustment coefficient is never directly observed. Therefore, here is one more contribution of this paper: to quantify the effects on the ruin probability and, consequently, on the insurer's solvency capital. 


\section{Theoretical background}

The literature on ruin theory is extensive and closely related to computational developments, which allowed advances in simulation processes and numerical approximation methods. There are several ways to estimate the ruin probability. Gatto and Mosimann (2012) explored four approaches to risk processes with compound Poisson. The main one is the approach via the Monte Carlo method (MCM), a stochastic simulation that provides an empirical approach to the ruin probability calculation. More recently, Touazi, Benouaret, Aissani and Adjabi (2017) - using a non-parametric approach -, Bareche and Cherfaoui (2019) and Gatto (2020) both using heavy-tail distributions - demonstrated that the estimates obtained by the simulation methods are strongly stable.

With the evolution of theories on bankruptcy analysis and the computational techniques improvement, it was possible to incorporate risk transfer mechanisms. Albrecher and Haas (2011) studied the ruin probability behavior of an insurance company that had an XL/R reinsurance contract, with reinstatement premiums. By varying reinstatements and the ceded premium (percentage of total premium), they found that an increase in the number of reinstatements does not necessarily imply a proportional reduction in the ruin probability. This fact is explained by the risk reduction (through the reinsurance coverage expansion) and the simultaneous increase in the reinsurance premium.

When the ceded premium percentage, security loading, and number of reinstatements were fixed, the authors identified that there is a reduction in the ruin probability the greater the initial capital is, whose relationship is given by an exponential decay. Furthermore, when compared to the base scenario (without any kind of risk transfer), the insertion of an XL/R reinsurance treaty decreases the probability of going bankrupt for the same initial capital, if the cedent and reinsurer's security loadings are similar.

Charpentier (2010) sought to understand the relationship between reinsurance, ruin, and solvency, paying attention to some pitfalls that, due to a lack of detailed technical analysis, can lead to an increase in the estimated number of bankruptcies, contrary to what is expected in view of the risk transfer mechanism implementation. His first finding was that quota share reinsurance treaties cannot increase the insurer's ruin probability, as expected. Through a numerical exercise, he concluded that proportional reinsurance, however, may not be the most efficient in reducing the ruin probability when claims have heavy tails.
For the non-proportional, in particular for excess of loss per risk treaties, the first observation is that this type of treaty is unfavorable when large amounts of claims with low severity occur, thus not exceeding the contractual priority. In this scenario, it is possible that the ruin probability will increase even with the presence of reinsurance, when compared to the scenario without the presence of reinsurance. Charpentier (2010) exemplifies that subtle changes in the priority value can compromise the company's solvency, since the net premium decreases more than the net claims, aggravating the ruin probability. For a non-homogeneous Poisson process with dependence between severity and claims frequency, the same non-intuitive conclusion is reached: the adoption of reinsurance leads to a riskier portfolio.

Restrictions establishment is also a concern of theoretical actuaries. From a mathematical point of view, Lefèvre, Trufin and Zuyderhoff (2017) demonstrate that not only the claims distribution but also the ordering of claim values influences the ruin probabilities assessment. But it is not just claims ordinances that matter: Dickson and Qazvini (2016) assess the role of reinsurers to minimize abrupt falls in the insurer's adjusted equity. Ramsden and Papaioannou (2019) introduce order on the capital level, arguing that the firm could take out loans from third parties (not just insurance companies), in case of insufficient own equity and difficulties in recapitalize its financial position, as a result of the shareholder confidence loss. In this case, the authors derive explicit expressions for the moments generating function of accumulated capital injections until the moment of bankruptcy, making it possible to estimate the ruin probability and dividend payments.

The literature continues to develop new theoretical approaches to better approximate the ruin probability numerical estimation, focusing on models that are more representative of risk processes than those based on the compound Poisson distribution. Wüthrich (2015) assesses coherent risk measures (such as expected shortfall), financial returns, and insurance liabilities pricing. Cheng, Gao and Wang (2016) use stochastic premiums. Tamturk and Utev (2018) use quantum mechanics to derive expressions for the ruin probability. Interestingly, despite the complex approach, the results are similar to the Markovian approach.

Some authors argue that the independence hypothesis between the severity and claims occurrences may not be realistic for certain portfolios (Cheung, Dai, \& Ni, 2018; Eryilmaz \& Gebizlioglu, 2017). In a similar line, but imposing a dependence structure between the claims occurrences in different lines of business, Dong and Wang (2018) use renovation processes with 
stochastic financial returns to derive asymptotic formulas for the ruin probability in finite and infinite time. Still incorporating dependence, there are authors who prove how the ruin probabilities can be affected by the tail dependence structure between financial and insurance risks (Chen \& Yuan, 2017; Constantinescu, Kozubowski, \& Qian, 2019; Vidmar, 2018).

In Brazilian literature, a dependence structure between events has also been incorporated. Melo (2008) proposes a Lévy Copulas application for a ruin multivariate process evaluation. It was assumed that there is a dependence structure between the aggregate claims of different lines of business, so that some segments subsidize others. It is concluded that the ruin probability is underestimated if the independence hypothesis in the data is assumed. Thus, comprehensive lines may be the most sensitive because an exogenous event can result in different coverage claims.

It is noteworthy the great scarcity of applied papers that use real microdata (Afonso, Cardoso, Reis, \& Guerreiro, 2017), mainly in national literature. Lemos (2008) tests classic methodologies through simulation with light and heavy tails distributions. However, reinsurance structures and their effects on ruin probability estimates have not been incorporated, and this is the gap that is intended to be filled.

Finally, it is important to highlight that the present paper is one of the rare cases - even in the international context - in which real microdata are used, respecting the peculiarities of each insurance line of business, to obtain accurate ruin probability estimates. It is an effective contribution to the national scientific knowledge about the insurance risk management strategies modeling.

\section{METHOD}

\section{The Cramér-Lundberg process}

To estimate the ruin probability, the CramérLundberg risk process will be simulated, which can be understood as a stochastic model that measures variations in the insurance company's adjusted equity over time. The process mathematical structure is:

$$
U_{t}=U_{t-1}+P_{t}-S_{t},
$$

for all $t>0$ and so that $U_{0}$ is the initial capital (free reserves, non-negative) of the insurance company, $P_{t}=(1+\theta) \mathbb{E}\left[S_{t}\right]$ are the collective premiums collected at time $t, \theta>0$, the safety loading, and $S_{t}$ is the collective claim at the same time $t$ defined as a random sum of random variables:

$$
S_{t}=X_{1}+X_{2}+X_{3}+\ldots+X_{N(t)}
$$

where $N(t)$ represents the number of claims occurred in $t$ and $X_{i}, \forall i=1, \ldots, n$, independent and identically distributed non-negative random variables, with $\mathbb{P}\left[X_{i}>0\right]=p$, independent of $N(t)=n, \forall n \in \mathbb{R}_{+}$, representing the individual severity of each claim. Therefore, $S_{t}$ is a convolution between frequency and severity of losses. Finally, it should be noted that all the random variables that determine the risk process (i.e., both the frequency and severity generators of each line of business) are invariant over time.

Exactly because the risk process input variables defined by Equation (2) conduct the dynamics of an insurer's essential operation, i.e., premium collection and claims payment, the Cramér-Lundberg model is appropriate to measure only the capital based on underwriting risk. All other types of risk have their own methodologies for their calculation.

Definition (ruin probability). Ruin occurs if the risk process defined by Equation (2) reached a negative value. The ruin probability is a measure of this event, such that:

$$
\psi\left(U_{0}\right)=\mathbb{P}\left[U_{t}<0 \mid U_{0}\right]
$$

From the temporal development, the time until ruin is defined as:

$$
T=\left\{\begin{array}{c}
\min \left\{t>0: U_{t}<0\right\}, \text { if this minimum exists, } \\
\infty, \text { otherwise } .
\end{array}\right.
$$

Therefore, this is the very first moment that the insurer is declared bankrupt. The ruin probability can also be expressed by $\psi\left(U_{0}\right)=\mathbb{P}\left[T<\infty \mid U_{0}\right]$. Thus, it is evident that the balance sheet has a statistical-actuarial perspective. Among the capital requirements that make up an insurer's balance sheet, there are technical provisions, obtained through the aggregate loss expected value. As these technical provisions are charged by $\theta$, we have the prudence margin for technical provisions. Still on the liability scale, in addition to the prudence margin, the solvency capital $\left(U_{0}\right)$ makes up the entity's adjusted equity.

The unawareness of the aggregate claim true distribution implies ignorance of the ruin probability. Therefore, all these accounts are random variables that have mean and variance, showing that an expressive and relevant portion of an insurer's balance sheet is endowed with uncertainty. Therefore, if the functional is incorrectly sized, the balance sheet will not adequately reflect the most reliable information regarding its financial situation. 


\section{Simulation procedure}

In this section, the simulation procedures are detailed, in order to estimate the ruin probabilities. The first stage will consist in the microdata base segregation, according to the allocation of each policy in the Susep's line of business (LoB) codification. This split is necessary because each business has its own dynamics for the claims' occurrence, requiring different probabilistic distributions assumption, both in frequency and in severity.

In the second stage, the severity distribution of each line of business will be estimated, with the objective of (a) computing the convolutions of each LoB by Equation (3), and (b) dimension the corresponding premiums for each LoB. Thus, it will be possible to assess the dynamics of the total number of policyholders present in each LoB portfolio, as well as the historical number of policies that incur claims. While the first amount will form the volume of premiums paid to the insurer, the second frequency represents the $N(t)$ in Equation (3).

Once these two steps have been carried out, MCM will be used to develop the simulations of the process given by Equation (2). According to Coulibaly and Lefèvre (2008), MCM is commonly used to simulate problems that can be represented by stochastic processes. The enforcement of this method does not guarantee the achievement of the exact solution. However, with the increase on the number of iterations it is possible to achieve an accurate estimate of the true value, as a sufficiently large number of simulations are processed (Gatto \& Mosimann, 2012). In addition, the MCM creates a wide spectrum of possible random scenarios based on the adjusted parameters calibration (Mikosch \& Samorodnitsky, 2000; Touazi, Benouaret, Aissani, \& Adjabi, 2017).

The insurer's contractual revenue and expense operations without incorporating instruments to limit contractual guarantees (reinsurance) will be considered as the base scenario. Thus, the technique will consist of repeating the simulations, for each LoB, 100,000 times, in order to reproduce the risk process' future trajectories defined by Equation (2). By the Law of Large Numbers (Baumgartner \& Gatto, 2010), if the number of iterations is large enough, it is possible to guarantee convergence between the simulated statistics and the respective real functional values. Once this procedure is performed, the ruin probability estimator $(\hat{\psi})$ is:

$$
\widehat{\psi}_{s}\left(U_{0}\right)=\frac{\#\left(U_{t}<0: \text { for some } t>0\right)}{r}
$$

where $s$ is the Susep LoB considered and $r$ the total number of replications/simulations. Additionally, for both base and modified scenario analyses (described below), variations on $U_{0}$ will be made to dimension the solvency capital of each LoB.

From the base scenario results, the next step is to incorporate into the claims probabilistic distributions the reinsurance treaties defined by Equation (1), including variations of the priority and quota share size. These modifications will make it possible to observe the effects that the risk transfer mechanisms have on solvency, paying attention to the claims amounts variability, the results stability, and the exponential decay relationship between initial capital and ruin probability.

\section{The database}

The database used contains 3,917,863 policies, segregated into $30 \mathrm{LoB}$ coded by Susep, with their respective issues made at some point in the time between Jan 1, 2015 and May 1, 2018, comprising three years of issuance and claims occurrence. The reason for the segregation into $\mathrm{LoB}$ is that there is disparity in relation to the contract general conditions, risk specificities, exclusion clauses, and other characteristics, including insurance contractual lifetime standards: each policy has its own contractual duration. For this reason, all contracts were brought on an annual basis (most common situation in the sector), to be included in the Cramér-Lundberg model, a process whose development takes place as variations in the result between revenues (from premiums) and expenses (from claims), which is fundamentally based on the cash basis accounting (and, in this particular paper, on annual basis).

In order to mitigate possible temporal disparities from events generated on accrual basis, all information of premiums, case reserves (CR), claims paid, and reinsurance recoveries were annualized to adjust the exposure of these policies. This methodological option is a simplifying hypothesis, which could generate some bias in the estimates. Despite the fact that the average duration of the $3,917,863$ policies is 327 days (with a standard deviation of 110 days), this problem does not compromise the estimates obtained by MCM on annual basis, which, as argued throughout the paper, are strongly stable (Bareche \& Cherfaoui, 2019; Gatto, 2020), mitigating eventual problems of this nature. Furthermore, as the process simulation is based on collective risk modeling, the individual policies effect is diluted in the line of business' standard set.

Thus, given a policy of $n$ years of lifetime, the premium paid by the insured was divided by $n$, so that the premium portion corresponds to one year of coverage. This rationale was also applied to the claim portion. 
Therefore, if this policy has claimed, the amount spent by the insurer has also been divided by $n$. So the direct comparison between income and expenses, per policy, becomes possible, since both information is on the same time basis.

Finally, it is noteworthy that the original data were uniformly transformed to guarantee the confidentiality of the entity that provided the records, while maintaining proportionality between them.

\section{Descriptive statistics and the claims distributions adjustment}

For the individual severity calculation, the CR amount was added to the payments made up to the initial date of data extraction, as the paper interest is the total effective cost related to each policy. In other words, for claims whose regulation has already been closed, the total cost is equal to the annualized payment amount, while for pending cases (outstanding) the total cost is equal to the sum of the provision (best estimate of future expenditures) with the annualized payment amount until the base date. This information is brought in Table 1.

After analyzing the dynamics of each LoB regarding premium collection, claims frequency, average values, and standard deviation, respectively, the next step was to adjust the claims probabilistic distribution. For this, by Susep's LoB definition, the most adherent distribution was adjusted to the business characteristics, as well as the associated parameters, since different LoBs may have the same distribution, but with different parameters.

The adjusted densities were: Exponential, Gamma, Normal, Log-Normal, Weibull, Inverse Weibull, and Pareto, with the parameters estimated through the methods of moments (MoM) and maximum likelihood estimation (MLE). The indicator chosen for the best model selection was the Bayesian Information Criterion (BIC), seeking its minimum.

Table 2 shows that there is a Log-Normal recurrence due to its skewness shape. Still, for the LoB that usually have greater kurtosis, the Pareto distribution stood out. It should be noted that during the paper development, the Log-Logistic and t-Student distributions were also tested, being chosen as the best distributions for some
LoB. However, as much as they could capture tail claims (outliers), this fact reflected significantly in the generation of high severity claims, affecting, consequently, both the simulations average and aggregate claims amount. Therefore, the distribution final choice considered not only a purely statistical indicator, but also a qualitative backtest of the ability to generate reliable observations of real claims.

After selecting the best model by LoB, the next step was to generate 10,000 possible scenarios for aggregate claims. The frequency was adjusted by a Poisson distribution with a parameter equal to the observed claims average in the database, as well as the severity through the distribution chosen in Table 2, with its respective parameters by LoB. In order to give robustness to the study, the frequency was also modeled by a Negative Binomial (Compound Pólya). However, this case generated claims observations exceedingly greater than the real numbers, thus increasing the aggregate loss and the ruin probability, by LoB. Therefore, it was decided to follow the literature, running the simulations as a compound Poisson process.

Given the randomness in generating the claims amount, the limit of indemnity (LoI) of each LoB was defined as twice the largest claim observed in the database, under the argument that the presence of claims with unrealistic values (because the insurer does not underwrite risks of this magnitude) would bias the risk process final analysis. Therefore, amounts that exceeded this LoI were excluded from the aggregate claim.

A sensitivity analysis was carried out, in which immateriality was found in the number of excluded claims, because, on average, only $0.37 \%$ of the claims generated in the 10,000 simulations were deleted. This analysis was also performed for scenarios with 100 and 1,000 simulations, which presented an exclusion rate of $0.34 \%$ and $0.37 \%$, respectively. In other words, increasing the number of simulations does not imply a proportional increase in the exclusion percentage, ensuring the feasibility of its application in the study. 
Table 1. Database descriptive statistics by Susep line of business (LoB).

\begin{tabular}{|c|c|c|c|c|c|c|c|c|c|}
\hline $\begin{array}{c}\text { Susep } \\
\text { LoB }\end{array}$ & LoB description & $\begin{array}{c}\text { Number of } \\
\text { policies }\end{array}$ & $\begin{array}{l}\text { Average } \\
\text { premium }\end{array}$ & $\begin{array}{l}\text { Maximum } \\
\text { premium }\end{array}$ & $\begin{array}{l}\text { Minimum } \\
\text { premium }\end{array}$ & $\begin{array}{l}\text { Number of } \\
\text { claims }\end{array}$ & $\begin{array}{l}\text { Average } \\
\text { severity }\end{array}$ & $\begin{array}{l}\text { Maximum } \\
\text { severity }\end{array}$ & $\begin{array}{c}\text { Minimum } \\
\text { severity }\end{array}$ \\
\hline 0114 & Homeowners & 104,912 & 443 & 201,221 & 23 & 3,665 & 3,170 & 133,009 & 50 \\
\hline 0115 & Theft & 24,579 & 1,438 & $3,555,903$ & 78 & 1,724 & 14,144 & $5,528,754$ & 50 \\
\hline 0116 & Condominium & 133,069 & 2,200 & 188,218 & 167 & 15,497 & 7,774 & $3,416,440$ & 22 \\
\hline 0118 & Business Insurance & 159,848 & 1,900 & 501,630 & 29 & 9,368 & 13,423 & $6,639,786$ & 40 \\
\hline 0141 & Business Interruption & 3,007 & 40,693 & $22,530,363$ & 78 & 149 & 55,914 & $1,464,188$ & 50 \\
\hline 0167 & Engineering Risks & 1,661 & 20,824 & $2,652,080$ & 278 & 129 & 100,087 & $2,910,709$ & 200 \\
\hline 0171 & Sundry Risks & 27,554 & 7,481 & $10,250,780$ & 94 & 1,522 & 69,905 & $3,372,572$ & 120 \\
\hline 0196 & Named and Operat. Risks & 1,404 & 298,618 & $22,985,034$ & 275 & 226 & $1,985,611$ & $211,148,985$ & 160 \\
\hline 0310 & Directors \& Officers & 889 & 21,462 & 661,213 & 1,121 & 32 & 145,214 & 725,332 & 5,090 \\
\hline 0351 & General Civil Liability & 14,610 & 14,864 & $8,963,370$ & 19 & 1,123 & 76,978 & $9,132,978$ & 50 \\
\hline 0378 & Professional Civil Liability & 2,431 & 21,506 & $2,010,760$ & 224 & 195 & 82,091 & $3,002,375$ & 303 \\
\hline 0520 & Passengers' Personal Accid. & 127,018 & 2,286 & 352,673 & 70 & 15,445 & 31,725 & 578,717 & 70 \\
\hline 0531 & Vehicle Insurance - Hull & $2,716,996$ & 2,056 & $8,527,948$ & 144 & 209,931 & 10,535 & $1,373,636$ & 21 \\
\hline 0542 & Vehicle Assistance \& Others & 1,101 & 7,461 & 174,011 & 707 & 113 & 23,195 & 172,602 & 165 \\
\hline 0553 & Motor Third Party Liability & 12,698 & 8,213 & $1,903,616$ & 353 & 1,989 & 19,437 & $1,313,308$ & 70 \\
\hline 0622 & International Cargo & 1,374 & 2,558 & $1,968,857$ & 11 & 28 & 10,265 & 90,062 & 22 \\
\hline 0776 & Guarantee — Private Sector & 750 & 19,484 & $1,428,468$ & 89 & 18 & 54,233 & 180,500 & 100 \\
\hline 0929 & Funeral Insurance & 172 & 2,655 & 12,897 & 124 & 24 & 14,408 & 190,966 & 359 \\
\hline 0982 & Collective Accident & 1,078 & 10,496 & 804,270 & 50 & 69 & 42,926 & 346,454 & 80 \\
\hline 0993 & Group Life Insurance & 3,273 & 9,384 & $1,484,533$ & 59 & 279 & 64,837 & $1,294,180$ & 50 \\
\hline 1061 & Lenders' Mortgage & 41 & 816,594 & $4,872,770$ & 1,750 & 19 & 380,745 & $1,858,775$ & 12,753 \\
\hline 1065 & Mortgage - Others & 30 & 266,117 & $2,523,042$ & 611 & 12 & 40,799 & 171,917 & 743 \\
\hline 1107 & Forest without RISF & 724 & 46,663 & $8,998,143$ & 419 & 37 & 368,361 & $3,144,258$ & 1,903 \\
\hline 1108 & Forest with RISF & 56 & 16,906 & 163,688 & 978 & 11 & 309,346 & 603,246 & 54,737 \\
\hline 1130 & Farm Products & 33,046 & 3,081 & $1,876,238$ & 33 & 2,052 & 31,989 & $1,275,627$ & 50 \\
\hline 1162 & Rural pledge & 60,333 & 1,255 & $2,625,958$ & 50 & 1,310 & 30,467 & $1,693,228$ & 119 \\
\hline 1369 & Travel & 440,742 & 223 & 8,945 & 6 & 8,578 & 4,352 & 590,423 & 27 \\
\hline 1381 & Personal Accident & 5,650 & 426 & 23,363 & 19 & 80 & 20,321 & 239,264 & 100 \\
\hline 1391 & Life Insurance (Personal) & 30,252 & 715 & 369,394 & 13 & 85 & 143,205 & $2,053,441$ & 100 \\
\hline 1433 & Marine (Hull) & 8,565 & 5,300 & $2,635,601$ & 265 & 252 & 122,024 & $3,782,900$ & 865 \\
\hline
\end{tabular}

Note. Descriptive statistics of all active policies (claimed or not) between January 2015 and May 2018. Source: developed by the authors, based on microdata provided by an insurance company. 
Table 2. More adherent distributions and their respective parameters.

\begin{tabular}{|c|c|c|c|}
\hline Susep LoB & Chosen distribution & Parameter 1 & Parameter 2 \\
\hline 0114 & Pareto & 3.923732 & $8,971 \cdot 131000$ \\
\hline 0115 & Log-Normal & 7.874931 & 1.633912 \\
\hline 0116 & Log-Normal & 7.658535 & 1.676110 \\
\hline 0118 & Pareto & 1.475869 & $5,038.577000$ \\
\hline 0141 & Pareto & 0.612967 & $1,210.940000$ \\
\hline 0167 & Log-Normal & 9.473071 & 2.041693 \\
\hline 0171 & Log-Normal & 9.756488 & 1.820056 \\
\hline 0196 & Pareto & 0.494173 & $11,990.450000$ \\
\hline 0310 & Inverse Weibull & 0.713026 & $14,855.770000$ \\
\hline 0351 & Log-Normal & 8.719645 & 2.194422 \\
\hline 0378 & Log-Normal & 9.437439 & 1.877550 \\
\hline 0520 & Weibull & 1.163465 & $33,468.830000$ \\
\hline 0531 & Log-Normal & 8.576584 & 1.180336 \\
\hline 0542 & Pareto & 1.823012 & $22,083.000000$ \\
\hline 0553 & Log-Normal & 8.847384 & 1.364390 \\
\hline 0622 & Log-Normal & 7.107324 & 2.287613 \\
\hline 0776 & Weibull & 0.687407 & $44,799.860000$ \\
\hline 0929 & Log-Normal & 8.171670 & 1.481832 \\
\hline 0982 & Weibull & 0.575525 & $27,042.790000$ \\
\hline 0993 & Weibull & 0.531372 & $35,212.310000$ \\
\hline 1061 & Exponential & 0.000003 & - \\
\hline 1065 & Exponential & 0.000025 & - \\
\hline 1107 & Log-Normal & 11.239290 & 2.099462 \\
\hline 1108 & Weibull & 1.870992 & $348,268.600000$ \\
\hline 1130 & Pareto & 1.324501 & $13,649.750000$ \\
\hline 1162 & Log-Normal & 9.188282 & 1.510290 \\
\hline 1369 & Log-Normal & 7.492330 & 1.220113 \\
\hline 1381 & Weibull & 0.603155 & $13,780.910000$ \\
\hline 1391 & Weibull & 0.592405 & $88,280.090000$ \\
\hline 1433 & Log-Normal & 10.534710 & 1.490059 \\
\hline
\end{tabular}

Note. Parametric distribution adjusted to the severity standard of each Susep's LoB for claims observed between January 2015 and May 2018. Source: developed by the authors, based on microdata provided by an insurance company.

According to Table 3, the simulation procedure was absolutely capable of reproducing the occurrences patterns. In almost all LoBs, frequency, severity, and $S_{A g}$ were close to the real values. For those LoBs in which this did not occur, such as $0115,0141,0378$, or 0929 , the underestimation justification lies in the fact that there are one, two, or, at most, three claims that are completely different from the average. As more than 98\% of the values are close to the observed average, the chosen distributions reflect this fact and do not generate outliers of such magnitude. 
Table 3. Results from 10,000 simulations generated.

\begin{tabular}{|c|c|c|c|c|c|c|c|c|c|c|}
\hline $\begin{array}{l}\text { Susep } \\
\text { LoB }\end{array}$ & $\begin{array}{l}\text { Number of } \\
\text { real claims }\end{array}$ & $\begin{array}{l}\text { Average real } \\
\text { severity }\end{array}$ & $\begin{array}{l}\text { Real severity } \\
\text { standard } \\
\text { deviation }\end{array}$ & $\begin{array}{l}\text { Real aggregate } \\
\text { claims }\end{array}$ & $\begin{array}{l}\text { Number of } \\
\text { simulated } \\
\text { claims }\end{array}$ & $\begin{array}{l}\text { Simulated } \\
\text { claims } \\
\text { standard } \\
\text { deviation }\end{array}$ & $\begin{array}{l}\text { Average } \\
\text { simulated } \\
\text { severity }\end{array}$ & $\begin{array}{l}\text { Simulated } \\
\text { severity } \\
\text { standard } \\
\text { deviation }\end{array}$ & $\begin{array}{c}\text { Simulated } \\
\text { aggregate claims }\end{array}$ & $\begin{array}{c}\text { Simulated } \\
\text { aggregate } \\
\text { claims standard } \\
\text { deviation }\end{array}$ \\
\hline 0114 & 3,665 & 3,170 & 6,219 & $11,304,497$ & 3,664 & 60 & 3,068 & 71 & $11,241,646$ & 321,511 \\
\hline 0115 & 1,724 & 14,144 & 153,754 & $23,691,684$ & 1,724 & 42 & 9,993 & 851 & $17,224,825$ & $1,526,160$ \\
\hline 0116 & 15,497 & 7,774 & 37,514 & $115,973,402$ & 15,498 & 124 & 8,623 & 264 & $133,631,878$ & $4,226,332$ \\
\hline 0118 & 9,368 & 13,423 & 112,225 & $123,317,872$ & 9,368 & 97 & 10,226 & 681 & $95,801,861$ & $6,465,361$ \\
\hline 0141 & 149 & 55,914 & 235,608 & $8,051,606$ & 148 & 12 & 36,315 & 14,726 & $5,363,731$ & $2,211,263$ \\
\hline 0167 & 129 & 100,087 & 348,572 & $12,410,834$ & 129 & 11 & 86,632 & 26,583 & $11,157,005$ & $3,565,402$ \\
\hline 0171 & 1,522 & 69,905 & 175,689 & $102,341,011$ & 1,522 & 39 & 83,879 & 6,994 & $127,645,585$ & $11,145,762$ \\
\hline 0196 & 226 & $1,985,611$ & $15,971,559$ & $395,136,599$ & 225 & 15 & $2,313,002$ & $1,203,446$ & $519,986,423$ & $272,772,749$ \\
\hline 0310 & 32 & 145,214 & 225,743 & $3,194,702$ & 31 & 6 & 89,235 & 34,347 & $2,756,309$ & $1,152,132$ \\
\hline 0351 & 1,123 & 76,978 & 415,125 & $78,209,877$ & 1,123 & 34 & 63,111 & 10,664 & $70,877,974$ & $12,167,670$ \\
\hline 0378 & 195 & 82,091 & 300,082 & $9,933,014$ & 195 & 14 & 67,262 & 16,443 & $13,121,638$ & $3,346,181$ \\
\hline 0520 & 15,445 & 31,725 & 29,325 & $480,245,649$ & 15,445 & 124 & 31,743 & 221 & $490,292,785$ & $5,248,623$ \\
\hline 0531 & 209,931 & 10,535 & 18,919 & $2,094,995,096$ & 209,925 & 451 & 10,648 & 40 & $2,235,261,496$ & $9,717,617$ \\
\hline 0542 & 113 & 23,195 & 33,311 & $2,528,304$ & 112 & 11 & 22,246 & 3,399 & $2,496,865$ & 450,023 \\
\hline 0553 & 1,989 & 19,437 & 55,375 & $36,833,542$ & 1,989 & 44 & 17,618 & 902 & $35,046,728$ & $1,960,556$ \\
\hline 0622 & 28 & 10,265 & 21,634 & 215,570 & 28 & 5 & 7,765 & 3,769 & 214,409 & 110,012 \\
\hline 0776 & 18 & 54,233 & 57,041 & 921,957 & 18 & 4 & 51,057 & 15,954 & 909,918 & 351,544 \\
\hline 0929 & 24 & 14,408 & 39,268 & 345,787 & 24 & 5 & 10,148 & 4,641 & 243,210 & 118,570 \\
\hline 0982 & 69 & 42,926 & 74,669 & $2,833,139$ & 69 & 8 & 41,755 & 8,682 & $2,875,300$ & 685,610 \\
\hline 0993 & 279 & 64,837 & 145,872 & $17,181,765$ & 279 & 17 & 63,143 & 7,741 & $17,609,584$ & $2,379,540$ \\
\hline 1061 & 19 & 380,745 & 457,635 & $7,234,153$ & 19 & 4 & 380,539 & 89,980 & $7,200,097$ & $2,366,969$ \\
\hline 1065 & 12 & 40,799 & 47,816 & 489,587 & 12 & 3 & 40,598 & 12,331 & 487,979 & 200,162 \\
\hline 1107 & 37 & 368,361 & 640,511 & $12,892,629$ & 36 & 6 & 351,766 & 130,853 & $12,756,151$ & $5,126,124$ \\
\hline 1108 & 11 & 309,346 & 179,427 & $3,402,804$ & 11 & 3 & 308,670 & 54,199 & $3,398,395$ & $1,162,105$ \\
\hline 1130 & 2,052 & 31,989 & 83,250 & $63,753,243$ & 2,050 & 46 & 31,899 & 2,217 & $65,388,380$ & $4,746,168$ \\
\hline 1162 & 1,310 & 30,467 & 82,954 & $38,388,106$ & 1,310 & 36 & 30,331 & 2,226 & $39,730,908$ & $3,109,557$ \\
\hline 1369 & 8,578 & 4,352 & 14,203 & $29,768,255$ & 8,578 & 92 & 3,775 & 76 & $32,381,395$ & 729,853 \\
\hline 1381 & 80 & 20,321 & 34,979 & $1,442,772$ & 80 & 9 & 20,462 & 3,946 & $1,637,020$ & 365,818 \\
\hline 1391 & 85 & 143,205 & 297,613 & $11,886,047$ & 85 & 9 & 134,649 & 26,161 & $11,431,826$ & $2,521,761$ \\
\hline 1433 & 252 & 122,024 & 352,286 & $27,577,383$ & 252 & 16 & 111,985 & 17,288 & $28,214,144$ & $4,667,516$ \\
\hline
\end{tabular}

Note. From the second to the fifth column, the values effectively observed in the database by LoB are presented; from the sixth to the ninth column, the simulations' results are presented. The last two columns present the convolutions' results (between frequency and severity) for each line of business. Source: developed by the authors, based on microdata provided by an insurance company.

\section{RESULTS AND DISCUSSIONS}

\section{Base scenario}

For both the base scenario (Cramér-Lundberg risk process without reinsurance incorporation) and modified, 100,000 paths were simulated, in order to observe in how many of these the $U_{t}$ of Equation (2) became strictly less than zero. In addition, as the number of policies and claims frequency refers to three years of operation, the 100,000 trajectories considered 70 periods of evolution, which means 210 years of development over time. This number of periods was defined in view of the expectation considered acceptable by Solvency II: one ruin every 200 years $(0.5 \%)$, on average. 
The assumptions taken were: (a) stable portfolios, in which the inflows and outflows are balanced and with the same pattern, for all LoB; (b) the default percentage is equal to zero; and (b) premium collection is constant in each period and is equal to the number of policies times the calculated average premium. The $S_{A g}$ of each period was obtained through a random choice on the array of 10,000 possible scenarios mentioned in subsection 'Descriptive statistics and the claims distributions adjustment'.

Table 4 shows the estimated ruin probability in the base scenario (without reinsurance) for each line of business, according to different solvency capital values $\left(U_{0}\right)$, in order to assess their sensitivity to different initial reserve definitions.

Table 4. Estimated ruin probability (\%) by LoB and solvency capital.

\begin{tabular}{|c|c|c|c|c|c|c|c|c|c|c|c|c|c|}
\hline \multirow[b]{2}{*}{ LoB } & \multicolumn{13}{|c|}{ Solvency capital ${ }^{(1)}$} \\
\hline & 0 & 500 & 1,000 & 1,500 & 2,000 & 2,500 & 3,000 & 3,500 & 4,000 & 4,500 & 5,000 & 5,500 & 6,000 \\
\hline 0114 & 0.0 & 0.0 & 0.0 & 0.0 & 0.0 & 0.0 & 0.0 & 0.0 & 0.0 & 0.0 & 0.0 & 0.0 & 0.0 \\
\hline 0115 & 0.1 & 0.0 & 0.0 & 0.0 & 0.0 & 0.0 & 0.0 & 0.0 & 0.0 & 0.0 & 0.0 & 0.0 & 0.0 \\
\hline 0116 & 0.0 & 0.0 & 0.0 & 0.0 & 0.0 & 0.0 & 0.0 & 0.0 & 0.0 & 0.0 & 0.0 & 0.0 & 0.0 \\
\hline 0118 & 0.0 & 0.0 & 0.0 & 0.0 & 0.0 & 0.0 & 0.0 & 0.0 & 0.0 & 0.0 & 0.0 & 0.0 & 0.0 \\
\hline 0141 & 0.0 & 0.0 & 0.0 & 0.0 & 0.0 & 0.0 & 0.0 & 0.0 & 0.0 & 0.0 & 0.0 & 0.0 & 0.0 \\
\hline 0167 & 0.3 & 0.2 & 0.1 & 0.1 & 0.1 & 0.0 & 0.0 & 0.0 & 0.0 & 0.0 & 0.0 & 0.0 & 0.0 \\
\hline 0171 & 8.6 & 7.8 & 7.4 & 6.9 & 6.7 & 6.1 & 5.5 & 5.1 & 4.7 & 4.4 & 3.9 & 3.7 & 3.5 \\
\hline 0196 & 100 & 100 & 100 & 100 & 100 & 100 & 100 & 100 & 100 & 100 & 100 & 100 & 100 \\
\hline 0310 & 0.0 & 0.0 & 0.0 & 0.0 & 0.0 & 0.0 & 0.0 & 0.0 & 0.0 & 0.0 & 0.0 & 0.0 & 0.0 \\
\hline 0351 & 0.0 & 0.0 & 0.0 & 0.0 & 0.0 & 0.0 & 0.0 & 0.0 & 0.0 & 0.0 & 0.0 & 0.0 & 0.0 \\
\hline 0378 & 0.0 & 0.0 & 0.0 & 0.0 & 0.0 & 0.0 & 0.0 & 0.0 & 0.0 & 0.0 & 0.0 & 0.0 & 0.0 \\
\hline 0520 & 100 & 100 & 100 & 100 & 100 & 100 & 100 & 100 & 100 & 100 & 100 & 100 & 100 \\
\hline 0531 & 0.0 & 0.0 & 0.0 & 0.0 & 0.0 & 0.0 & 0.0 & 0.0 & 0.0 & 0.0 & 0.0 & 0.0 & 0.0 \\
\hline 0542 & 0.0 & 0.0 & 0.0 & 0.0 & 0.0 & 0.0 & 0.0 & 0.0 & 0.0 & 0.0 & 0.0 & 0.0 & 0.0 \\
\hline 0553 & 0.0 & 0.0 & 0.0 & 0.0 & 0.0 & 0.0 & 0.0 & 0.0 & 0.0 & 0.0 & 0.0 & 0.0 & 0.0 \\
\hline 0622 & 0.0 & 0.0 & 0.0 & 0.0 & 0.0 & 0.0 & 0.0 & 0.0 & 0.0 & 0.0 & 0.0 & 0.0 & 0.0 \\
\hline 0776 & 0.0 & 0.0 & 0.0 & 0.0 & 0.0 & 0.0 & 0.0 & 0.0 & 0.0 & 0.0 & 0.0 & 0.0 & 0.0 \\
\hline 0929 & 35.1 & 1.3 & 0.0 & 0.0 & 0.0 & 0.0 & 0.0 & 0.0 & 0.0 & 0.0 & 0.0 & 0.0 & 0.0 \\
\hline 0982 & 0.0 & 0.0 & 0.0 & 0.0 & 0.0 & 0.0 & 0.0 & 0.0 & 0.0 & 0.0 & 0.0 & 0.0 & 0.0 \\
\hline 0993 & 6.6 & 4.6 & 3.1 & 2.0 & 1.3 & 0.8 & 0.6 & 0.3 & 0.2 & 0.1 & 0.0 & 0.0 & 0.0 \\
\hline 1061 & 0.0 & 0.0 & 0.0 & 0.0 & 0.0 & 0.0 & 0.0 & 0.0 & 0.0 & 0.0 & 0.0 & 0.0 & 0.0 \\
\hline 1065 & 0.0 & 0.0 & 0.0 & 0.0 & 0.0 & 0.0 & 0.0 & 0.0 & 0.0 & 0.0 & 0.0 & 0.0 & 0.0 \\
\hline 1107 & 3.4 & 2.9 & 2.4 & 2.0 & 1.8 & 1.5 & 1.2 & 1.0 & 0.9 & 0.8 & 0.6 & 0.5 & 0.5 \\
\hline 1108 & 100 & 100 & 100 & 100 & 100 & 100 & 100 & 100 & 100 & 100 & 100 & 100 & 100 \\
\hline 1130 & 13.1 & 11.5 & 9.5 & 8.3 & 7.0 & 6.1 & 5.1 & 4.1 & 3.5 & 2.9 & 2.4 & 2.0 & 1.6 \\
\hline 1162 & 0.0 & 0.0 & 0.0 & 0.0 & 0.0 & 0.0 & 0.0 & 0.0 & 0.0 & 0.0 & 0.0 & 0.0 & 0.0 \\
\hline 1369 & 0.0 & 0.0 & 0.0 & 0.0 & 0.0 & 0.0 & 0.0 & 0.0 & 0.0 & 0.0 & 0.0 & 0.0 & 0.0 \\
\hline 1381 & 80.7 & 57.3 & 39.3 & 26.5 & 17.7 & 11.6 & 7.5 & 4.8 & 3.0 & 1.9 & 1.1 & 0.7 & 0.4 \\
\hline 1391 & 9.1 & 6.9 & 5.2 & 3.8 & 2.7 & 2.1 & 1.4 & 1.0 & 0.7 & 0.5 & 0.4 & 0.2 & 0.2 \\
\hline 1433 & 30.2 & 27.3 & 24.4 & 22.1 & 19.8 & 18.0 & 16.1 & 14.1 & 12.7 & 11.0 & 10.0 & 8.7 & 7.8 \\
\hline
\end{tabular}

Note. the ruin probability (\%) was estimated for each line of business from the 100,000 Monte Carlo simulations of the Cramér-Lundberg risk process, for different solvency capital levels, without reinsurance treaty. ${ }^{(1)}$ In BRL thousands. Source: developed by the authors, based on the simulations' outcomes. 
The first conclusion that Table 4 provides is that each LoB has its own dynamics. It is observed that several businesses present ruin probabilities close to zero (among which are important classes such as 0118, 0310, 0531, 0553, 1061) even with no solvency capital, while others have significant reductions with increases in the initial reserve (0171, 0929, 0993, 1130, 1381, among others). At the opposite extreme, some relevant LoBs (0196, 0520 , and 1108 ) continue with ruin probability equal to $100 \%$ or close to this level, even with high volumes of solvency capital. This (almost) certain ruin has as its main argument the fact that the claims of these businesses have high levels of reinsurance, preventing, precisely, that these insolvency scenarios materialize (the line 0196, for example, by Table 1 has the claim with greater severity of the database - approximately BRL 211 million).

Furthermore, the LoB 0520's (almost) certain ruin and the LoB 0531's ruin probability close to zero, perhaps, may be a signal that there is a cross subsidy, as the coverages are offered together when the policies are issued, which would make possible for the 0531's excess premium to oxygenate the LoB 0520's low result. For the LoB 1108, a possible explanation would be its own logical construction, since that the business contains coverage from the Rural Insurance Stability Fund (RISF), which aims to maintain and to guarantee the balance of the Brazilian agricultural operation, as well as to provide supplementary coverage to catastrophe risks, inherent to rural activity.

Thus, insurance companies can recover from the RISF, in forest insurance, the portion of their retained claims between $100 \%$ and $150 \%$ of loss ratio, as well as amounts that exceed $250 \%$ of loss ratio. I.e., exemplifying for a claim, net of reinsurance treaties and coinsurances, if this claim, individually, still exceeds $100 \%$ of loss ratio, the amounts incurred by the insurer that make up the excess to $100 \%$ may be recovered via RISF, limited to $150 \%$. Between $150 \%$ and $250 \%$ of loss ratio, the burden of the claim's severity rests entirely with the insurer; however, after exceeding $250 \%$, there is again the right to recovery through the RISF.

\section{Scenario with proportional reinsurance}

For this scenario, it was promoted the introduction of a proportional reinsurance (quota share treaty), transforming the original random variable, as Equation (1). Thus, the risk process was simulated with two different retention percentages $(\alpha)$, applied directly both to the premiums and aggregate claims amounts. The retention percentages defined in the study were $90 \%$ and $80 \%$, respectively, and the choice for these levels was based strictly on the insurer's Risk Policy guideline that provided the data, as well as on its reinsurance panel practiced in the fiscal year 2018. The methodological procedure adopted for the percentages' choice aims to attribute authenticity to the paper, since the assigned retentions and cessions are in line with the local regulator current practices.

As can be seen from the comparison of Tables 4 and 5 , the quota share proportional reinsurance imposition, due to its own operational design, allows the insurer to reduce the uncertainty of its results and, consequently, reduce the ruin probability for the same initial reserve level. Still, when confronting the risk transfer mechanism with different retention weights, it is evident that a reduction on the contractual $\alpha$ intensifies the estimated ruin probability decay to zero. As an example, Figure 1 exhibits the comparison of the functional's sensitivity for the LoB 0171.

However, it is noteworthy that for the LoBs identified as more unbalanced in subsection 'Base Scenario' (such as 0196, 0520, 1108, and 1381), the presence of a proportional reinsurance was not sufficient to make the businesses solvent per se. This evidence is partially explained by the fact that, regardless of the retention percentage defined, the most severe claims will cause high expenses to the insurer, because the burden of covered risk materialization will be destined to the parties involved (insurer and reinsurer) on the same premium transfer proportion. Thus, in practically all simulations, the retained premiums at a certain time during the risk processes are fully consumed by the tail claims, as well as the solvency reserve initially established.

\section{Scenario with non-proportional reinsurance}

For this scenario, was considered the imposition of a non-proportional reinsurance XL/R treaty, according to Equation (1). Thus, for each simulated claim, by line of business and by simulation (10,000 aggregate claim scenarios), an inspection was made on the individual severity amount: if this amount exceeded the business' priority, then its value was no longer the originally simulated, assuming the priority value. In other words, the individual severity of the simulated claims was truncated by the LoB priority, because this paper's interest is to assess from the insurer's perspective, and the excess becomes the reinsurer responsibility. 
Table 5. Estimated ruin probability (\%) by LoB and solvency capital - quota share with a $=90 \%$.

\begin{tabular}{|c|c|c|c|c|c|c|c|c|c|c|c|c|c|}
\hline \multirow[b]{2}{*}{ LoB } & \multicolumn{13}{|c|}{ Solvency capital ${ }^{(1)}$} \\
\hline & 0 & 500 & 1,000 & 1,500 & 2,000 & 2,500 & 3,000 & 3,500 & 4,000 & 4,500 & 5,000 & 5,500 & 6,000 \\
\hline 0114 & 0.0 & 0.0 & 0.0 & 0.0 & 0.0 & 0.0 & 0.0 & 0.0 & 0.0 & 0.0 & 0.0 & 0.0 & 0.0 \\
\hline 0115 & 0.1 & 0.0 & 0.0 & 0.0 & 0.0 & 0.0 & 0.0 & 0.0 & 0.0 & 0.0 & 0.0 & 0.0 & 0.0 \\
\hline 0116 & 0.0 & 0.0 & 0.0 & 0.0 & 0.0 & 0.0 & 0.0 & 0.0 & 0.0 & 0.0 & 0.0 & 0.0 & 0.0 \\
\hline 0118 & 0.0 & 0.0 & 0.0 & 0.0 & 0.0 & 0.0 & 0.0 & 0.0 & 0.0 & 0.0 & 0.0 & 0.0 & 0.0 \\
\hline 0141 & 0.0 & 0.0 & 0.0 & 0.0 & 0.0 & 0.0 & 0.0 & 0.0 & 0.0 & 0.0 & 0.0 & 0.0 & 0.0 \\
\hline 0167 & 0.3 & 0.2 & 0.2 & 0.1 & 0.1 & 0.1 & 0.0 & 0.1 & 0.0 & 0.0 & 0.0 & 0.0 & 0.0 \\
\hline 0171 & 8.1 & 7.6 & 6.9 & 6.3 & 5.8 & 5.3 & 5.0 & 4.6 & 4.2 & 3.7 & 3.4 & 3.0 & 2.8 \\
\hline 0196 & 100 & 100 & 100 & 100 & 100 & 100 & 100 & 100 & 100 & 100 & 100 & 100 & 100 \\
\hline 0310 & 0.0 & 0.0 & 0.0 & 0.0 & 0.0 & 0.0 & 0.0 & 0.0 & 0.0 & 0.0 & 0.0 & 0.0 & 0.0 \\
\hline 0351 & 0.0 & 0.0 & 0.0 & 0.0 & 0.0 & 0.0 & 0.0 & 0.0 & 0.0 & 0.0 & 0.0 & 0.0 & 0.0 \\
\hline 0378 & 0.0 & 0.0 & 0.0 & 0.0 & 0.0 & 0.0 & 0.0 & 0.0 & 0.0 & 0.0 & 0.0 & 0.0 & 0.0 \\
\hline 0520 & 100 & 100 & 100 & 100 & 100 & 100 & 100 & 100 & 100 & 100 & 100 & 100 & 100 \\
\hline 0531 & 0.0 & 0.0 & 0.0 & 0.0 & 0.0 & 0.0 & 0.0 & 0.0 & 0.0 & 0.0 & 0.0 & 0.0 & 0.0 \\
\hline 0542 & 0.0 & 0.0 & 0.0 & 0.0 & 0.0 & 0.0 & 0.0 & 0.0 & 0.0 & 0.0 & 0.0 & 0.0 & 0.0 \\
\hline 0553 & 0.0 & 0.0 & 0.0 & 0.0 & 0.0 & 0.0 & 0.0 & 0.0 & 0.0 & 0.0 & 0.0 & 0.0 & 0.0 \\
\hline 0622 & 0.0 & 0.0 & 0.0 & 0.0 & 0.0 & 0.0 & 0.0 & 0.0 & 0.0 & 0.0 & 0.0 & 0.0 & 0.0 \\
\hline 0776 & 0.0 & 0.0 & 0.0 & 0.0 & 0.0 & 0.0 & 0.0 & 0.0 & 0.0 & 0.0 & 0.0 & 0.0 & 0.0 \\
\hline 0929 & 34.9 & 0.8 & 0.0 & 0.0 & 0.0 & 0.0 & 0.0 & 0.0 & 0.0 & 0.0 & 0.0 & 0.0 & 0.0 \\
\hline 0982 & 0.0 & 0.0 & 0.0 & 0.0 & 0.0 & 0.0 & 0.0 & 0.0 & 0.0 & 0.0 & 0.0 & 0.0 & 0.0 \\
\hline 0993 & 7.0 & 4.6 & 3.1 & 2.0 & 1.2 & 0.7 & 0.4 & 0.3 & 0.1 & 0.1 & 0.1 & 0.0 & 0.0 \\
\hline 1061 & 0.0 & 0.0 & 0.0 & 0.0 & 0.0 & 0.0 & 0.0 & 0.0 & 0.0 & 0.0 & 0.0 & 0.0 & 0.0 \\
\hline 1065 & 0.0 & 0.0 & 0.0 & 0.0 & 0.0 & 0.0 & 0.0 & 0.0 & 0.0 & 0.0 & 0.0 & 0.0 & 0.0 \\
\hline 1107 & 3.4 & 2.9 & 2.4 & 1.9 & 1.5 & 1.3 & 1.0 & 0.8 & 0.7 & 0.6 & 0.5 & 0.4 & 0.4 \\
\hline 1108 & 100 & 100 & 100 & 100 & 100 & 100 & 100 & 100 & 100 & 100 & 100 & 100 & 100 \\
\hline 1130 & 13.9 & 11.9 & 10.1 & 8.4 & 7.1 & 5.9 & 5.0 & 4.0 & 3.4 & 2.7 & 2.0 & 1.7 & 1.3 \\
\hline 1162 & 0.0 & 0.0 & 0.0 & 0.0 & 0.0 & 0.0 & 0.0 & 0.0 & 0.0 & 0.0 & 0.0 & 0.0 & 0.0 \\
\hline 1369 & 0.0 & 0.0 & 0.0 & 0.0 & 0.0 & 0.0 & 0.0 & 0.0 & 0.0 & 0.0 & 0.0 & 0.0 & 0.0 \\
\hline 1381 & 81.0 & 54.8 & 35.2 & 22.6 & 14.0 & 8.8 & 5.1 & 3.0 & 1.8 & 1.1 & 0.6 & 0.3 & 0.2 \\
\hline 1391 & 10.3 & 7.8 & 5.2 & 3.7 & 2.7 & 1.8 & 1.3 & 1.0 & 0.6 & 0.4 & 0.3 & 0.2 & 0.2 \\
\hline 1433 & 29.3 & 26.4 & 23.2 & 20.5 & 18.2 & 16.1 & 13.9 & 12.7 & 10.9 & 9.7 & 8.3 & 7.3 & 6.5 \\
\hline
\end{tabular}

Note. The ruin probability (\%) was estimated for each line of business from the 100,000 Monte Carlo simulations of the Cramér-Lundberg risk process, for different solvency capital levels, with a quota share reinsurance $(\alpha=90 \%){ }^{(1)}$ In BRL thousands. Source: developed by the authors, based on the simulations' outcomes. 
Table 6. Estimated ruin probability (\%) by LoB and solvency capital - quota share with $a=80 \%$.

\begin{tabular}{|c|c|c|c|c|c|c|c|c|c|c|c|c|c|}
\hline \multicolumn{14}{|c|}{ Solvency capital ${ }^{(1)}$} \\
\hline LoB & 0 & 500 & 1,000 & 1,500 & 2,000 & 2,500 & 3,000 & 3,500 & 4,000 & 4,500 & 5,000 & 5,500 & 6,000 \\
\hline 0114 & 0.0 & 0.0 & 0.0 & 0.0 & 0.0 & 0.0 & 0.0 & 0.0 & 0.0 & 0.0 & 0.0 & 0.0 & 0.0 \\
\hline 0115 & 0.1 & 0.0 & 0.0 & 0.0 & 0.0 & 0.0 & 0.0 & 0.0 & 0.0 & 0.0 & 0.0 & 0.0 & 0.0 \\
\hline 0116 & 0.0 & 0.0 & 0.0 & 0.0 & 0.0 & 0.0 & 0.0 & 0.0 & 0.0 & 0.0 & 0.0 & 0.0 & 0.0 \\
\hline 0118 & 0.0 & 0.0 & 0.0 & 0.0 & 0.0 & 0.0 & 0.0 & 0.0 & 0.0 & 0.0 & 0.0 & 0.0 & 0.0 \\
\hline 0141 & 0.0 & 0.0 & 0.0 & 0.0 & 0.0 & 0.0 & 0.0 & 0.0 & 0.0 & 0.0 & 0.0 & 0.0 & 0.0 \\
\hline 0167 & 0.3 & 0.2 & 0.1 & 0.1 & 0.1 & 0.1 & 0.1 & 0.0 & 0.0 & 0.0 & 0.0 & 0.0 & 0.0 \\
\hline 0171 & 8.1 & 7.3 & 6.8 & 6.2 & 5.7 & 5.2 & 4.6 & 4.3 & 3.7 & 3.4 & 2.9 & 2.6 & 2.4 \\
\hline 0196 & 100 & 100 & 100 & 100 & 100 & 100 & 100 & 100 & 100 & 100 & 100 & 100 & 100 \\
\hline 0310 & 0.0 & 0.0 & 0.0 & 0.0 & 0.0 & 0.0 & 0.0 & 0.0 & 0.0 & 0.0 & 0.0 & 0.0 & 0.0 \\
\hline 0351 & 0.0 & 0.0 & 0.0 & 0.0 & 0.0 & 0.0 & 0.0 & 0.0 & 0.0 & 0.0 & 0.0 & 0.0 & 0.0 \\
\hline 0378 & 0.0 & 0.0 & 0.0 & 0.0 & 0.0 & 0.0 & 0.0 & 0.0 & 0.0 & 0.0 & 0.0 & 0.0 & 0.0 \\
\hline 0520 & 100 & 100 & 100 & 100 & 100 & 100 & 100 & 100 & 100 & 100 & 100 & 100 & 100 \\
\hline 0531 & 0.0 & 0.0 & 0.0 & 0.0 & 0.0 & 0.0 & 0.0 & 0.0 & 0.0 & 0.0 & 0.0 & 0.0 & 0.0 \\
\hline 0542 & 0.0 & 0.0 & 0.0 & 0.0 & 0.0 & 0.0 & 0.0 & 0.0 & 0.0 & 0.0 & 0.0 & 0.0 & 0.0 \\
\hline 0553 & 0.0 & 0.0 & 0.0 & 0.0 & 0.0 & 0.0 & 0.0 & 0.0 & 0.0 & 0.0 & 0.0 & 0.0 & 0.0 \\
\hline 0622 & 0.0 & 0.0 & 0.0 & 0.0 & 0.0 & 0.0 & 0.0 & 0.0 & 0.0 & 0.0 & 0.0 & 0.0 & 0.0 \\
\hline 0776 & 0.0 & 0.0 & 0.0 & 0.0 & 0.0 & 0.0 & 0.0 & 0.0 & 0.0 & 0.0 & 0.0 & 0.0 & 0.0 \\
\hline 0929 & 34.9 & 0.5 & 0.0 & 0.0 & 0.0 & 0.0 & 0.0 & 0.0 & 0.0 & 0.0 & 0.0 & 0.0 & 0.0 \\
\hline 0982 & 0.0 & 0.0 & 0.0 & 0.0 & 0.0 & 0.0 & 0.0 & 0.0 & 0.0 & 0.0 & 0.0 & 0.0 & 0.0 \\
\hline 0993 & 6.9 & 4.4 & 2.8 & 1.6 & 1.0 & 0.5 & 0.3 & 0.1 & 0.1 & 0.1 & 0.0 & 0.0 & 0.0 \\
\hline 1061 & 0.0 & 0.0 & 0.0 & 0.0 & 0.0 & 0.0 & 0.0 & 0.0 & 0.0 & 0.0 & 0.0 & 0.0 & 0.0 \\
\hline 1065 & 0.0 & 0.0 & 0.0 & 0.0 & 0.0 & 0.0 & 0.0 & 0.0 & 0.0 & 0.0 & 0.0 & 0.0 & 0.0 \\
\hline 1107 & 3.6 & 2.7 & 2.2 & 1.7 & 1.4 & 1.1 & 1.0 & 0.7 & 0.6 & 0.5 & 0.4 & 0.3 & 0.3 \\
\hline 1108 & 100 & 100 & 100 & 100 & 100 & 100 & 100 & 100 & 100 & 100 & 100 & 100 & 100 \\
\hline 1130 & 13.9 & 11.5 & 9.6 & 7.9 & 6.5 & 5.2 & 4.3 & 3.5 & 2.7 & 2.0 & 1.6 & 1.3 & 1.0 \\
\hline 1162 & 0.0 & 0.0 & 0.0 & 0.0 & 0.0 & 0.0 & 0.0 & 0.0 & 0.0 & 0.0 & 0.0 & 0.0 & 0.0 \\
\hline 1369 & 0.0 & 0.0 & 0.0 & 0.0 & 0.0 & 0.0 & 0.0 & 0.0 & 0.0 & 0.0 & 0.0 & 0.0 & 0.0 \\
\hline 1381 & 81.1 & 51.8 & 31.6 & 18.9 & 11.1 & 6.4 & 3.5 & 1.9 & 1.0 & 0.6 & 0.3 & 0.1 & 0.0 \\
\hline 1391 & 10.1 & 7.2 & 5.1 & 3.4 & 2.2 & 1.5 & 1.1 & 0.7 & 0.5 & 0.3 & 0.2 & 0.2 & 0.1 \\
\hline 1433 & 29.2 & 25.7 & 22.6 & 19.6 & 16.7 & 14.9 & 12.8 & 11.4 & 9.7 & 8.3 & 7.2 & 6.1 & 5.3 \\
\hline
\end{tabular}

Note. The ruin probability (\%) was estimated for each line of business from the 100,000 Monte Carlo simulations of the Cramér-Lundberg risk process, for different solvency capital levels, with a quota share reinsurance $(\alpha=80 \%)$. ${ }^{(1)}$ In BRL thousands. Source: developed by the authors, based on the simulations' outcomes.

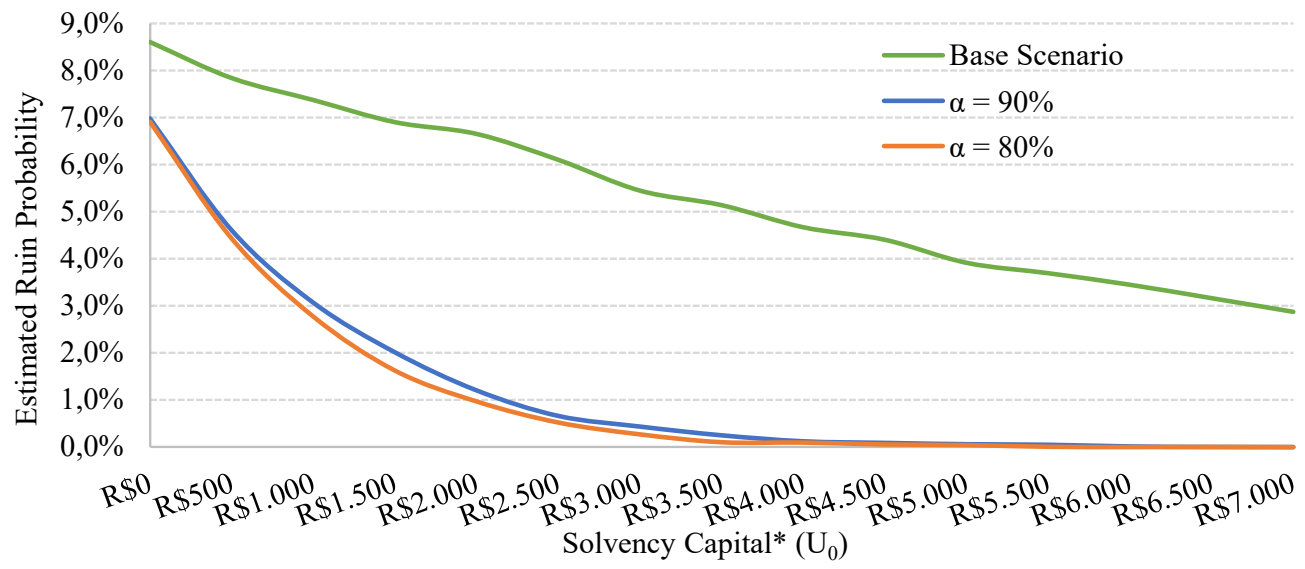

Figure 1. Estimated ruin probability - scenarios comparison for LoB 0171.

*The solvency capital values are expressed in BRL thousands. Source: developed by the authors. 
Initially, the priority choice, by line of business, was made in view of the RL reported on the official platform SES-Susep, as of August 2018. However, it was found that the claims history, in general, did not contain severities that exceeded the reported RL. Thus, the extraction values were assumed as a reinsurance contract priority only for the LoBs whose assumption was applicable. These lines of business are detailed in Table 7.

For the other lines of business, an analysis was carried out to verify what should be the contract priority in order to transfer to the reinsurer approximately the same proportion of the businesses whose limit choice was made through SESSusep.

Table 7. Priority description considered (in BRL) via SES-Susep.

\begin{tabular}{|c|c|c|c|c|}
\hline Susep LoB & Line description & Real maximum severity & Retention limit reported & $\begin{array}{c}\text { Priority considered for the excess } \\
\text { of loss }\end{array}$ \\
\hline 0114 & Homeowners & 133,009 & $10,000,000$ & 66,000 \\
\hline 0115 & Theft & $5,528,754$ & $10,000,000$ & $2,700,000$ \\
\hline 0116 & Condominium & $3,416,440$ & $10,000,000$ & $1,700,000$ \\
\hline 0118 & Business Insurance & $6,639,786$ & $10,000,000$ & $3,300,000$ \\
\hline 0141 & Business Interruption & $1,464,188$ & $10,000,000$ & 700,000 \\
\hline 0167 & Engineering Risks & $2,910,709$ & $10,000,000$ & $1,500,000$ \\
\hline 0171 & Sundry Risks & $3,372,572$ & $10,000,000$ & $1,700,000$ \\
\hline 0196 & Named and Operat. Risks & $211,148,985$ & $10,000,000$ & $10,000,000$ \\
\hline 0310 & Directors \& Officers & 725,332 & $2,000,000$ & 360,000 \\
\hline 0351 & General Civil Liability & $9,132,978$ & $2,000,000$ & $2,000,000$ \\
\hline 0378 & Professional Civil Liability & $3,002,375$ & $2,000,000$ & $2,000,000$ \\
\hline 0520 & Passengers' Personal Accid. & 578,717 & $1,910,938$ & 22,000 \\
\hline 0531 & Vehicle Insurance — Hull & $1,373,636$ & $1,910,938$ & 680,000 \\
\hline 0542 & Vehicle Assistance \& Others & 172,602 & $1,910,938$ & 85,000 \\
\hline 0553 & Motor Third Party Liability & $1,313,308$ & $3,500,000$ & 650,000 \\
\hline 0622 & International Cargo & 90,062 & $4,000,000$ & 44,000 \\
\hline 0776 & Guarantee — Private Sector & 180,500 & $5,000,000$ & 90,000 \\
\hline 0929 & Funeral Insurance & 190,966 & $1,500,000$ & 95,000 \\
\hline 0982 & Collective Accident & 346,454 & $1,910,938$ & 170,000 \\
\hline 0993 & Group Life Insurance & $1,294,180$ & $1,910,938$ & 641,000 \\
\hline 1061 & Lenders' Mortgage & $1,858,775$ & $5,000,000$ & 920,000 \\
\hline 1065 & Mortgage - Others & 171,917 & $10,000,000$ & 85,000 \\
\hline 1107 & Forest without RISF & $3,144,258$ & $3,000,000$ & $3,000,000$ \\
\hline 1108 & Forest with RISF & 603,246 & $3,000,000$ & 75,000 \\
\hline 1130 & Farm Products & $1,275,627$ & $10,000,000$ & 630,000 \\
\hline 1162 & Rural pledge & $1,693,228$ & $10,000,000$ & 840,000 \\
\hline 1369 & Travel & 590,423 & $1,910,938$ & 290,000 \\
\hline 1381 & Personal Accident & 239,264 & $1,910,938$ & 118,000 \\
\hline 1391 & Life Insurance (Personal) & $2,053,441$ & $1,910,938$ & $1,910,938$ \\
\hline 1433 & Marine (Hull) & $3,782,900$ & $2,000,000$ & $2,000,000$ \\
\hline
\end{tabular}

Note. The table shows a comparison between the highest severity (in BRL) observed in the database and the retention limit (priority) informed by the insurer to Susep. This official priority was used to impose a risk transfer threshold for the reinsurer. Specifically, for the LoBs in which all severities observed were below the defined priority, it was decided to transfer to the reinsurer the same proportion of the LoBs whose limit choice was made through the SES-Susep. Source: developed by the authors, based on the database and SES-Susep. 
Table 8. Estimated ruin probability (\%) by LoB and solvency capital — excess of loss per risk.

\begin{tabular}{|c|c|c|c|c|c|c|c|c|c|c|c|c|c|}
\hline \multirow[b]{2}{*}{ LoB } & \multicolumn{13}{|c|}{ Solvency capital $^{(1)}$} \\
\hline & 0 & 500 & 1,000 & 1,500 & 2,000 & 2,500 & 3,000 & 3,500 & 4,000 & 4,500 & 5,000 & 5,500 & 6,000 \\
\hline 0114 & 0.0 & 0.0 & 0.0 & 0.0 & 0.0 & 0.0 & 0.0 & 0.0 & 0.0 & 0.0 & 0.0 & 0.0 & 0.0 \\
\hline 0115 & 0.0 & 0.0 & 0.0 & 0.0 & 0.0 & 0.0 & 0.0 & 0.0 & 0.0 & 0.0 & 0.0 & 0.0 & 0.0 \\
\hline 0116 & 0.0 & 0.0 & 0.0 & 0.0 & 0.0 & 0.0 & 0.0 & 0.0 & 0.0 & 0.0 & 0.0 & 0.0 & 0.0 \\
\hline 0118 & 0.0 & 0.0 & 0.0 & 0.0 & 0.0 & 0.0 & 0.0 & 0.0 & 0.0 & 0.0 & 0.0 & 0.0 & 0.0 \\
\hline 0141 & 0.0 & 0.0 & 0.0 & 0.0 & 0.0 & 0.0 & 0.0 & 0.0 & 0.0 & 0.0 & 0.0 & 0.0 & 0.0 \\
\hline 0167 & 0.0 & 0.0 & 0.0 & 0.0 & 0.0 & 0.0 & 0.0 & 0.0 & 0.0 & 0.0 & 0.0 & 0.0 & 0.0 \\
\hline 0171 & 0.0 & 0.0 & 0.0 & 0.0 & 0.0 & 0.0 & 0.0 & 0.0 & 0.0 & 0.0 & 0.0 & 0.0 & 0.0 \\
\hline 0196 & 0.0 & 0.0 & 0.0 & 0.0 & 0.0 & 0.0 & 0.0 & 0.0 & 0.0 & 0.0 & 0.0 & 0.0 & 0.0 \\
\hline 0310 & 0.0 & 0.0 & 0.0 & 0.0 & 0.0 & 0.0 & 0.0 & 0.0 & 0.0 & 0.0 & 0.0 & 0.0 & 0.0 \\
\hline 0351 & 0.0 & 0.0 & 0.0 & 0.0 & 0.0 & 0.0 & 0.0 & 0.0 & 0.0 & 0.0 & 0.0 & 0.0 & 0.0 \\
\hline 0378 & 0.0 & 0.0 & 0.0 & 0.0 & 0.0 & 0.0 & 0.0 & 0.0 & 0.0 & 0.0 & 0.0 & 0.0 & 0.0 \\
\hline 0520 & 43.4 & 36.3 & 30.4 & 24.7 & 20.0 & 16.1 & 12.6 & 9.8 & 7.8 & 6.1 & 4.8 & 3.8 & 3.0 \\
\hline 0531 & 0.0 & 0.0 & 0.0 & 0.0 & 0.0 & 0.0 & 0.0 & 0.0 & 0.0 & 0.0 & 0.0 & 0.0 & 0.0 \\
\hline 0542 & 0.0 & 0.0 & 0.0 & 0.0 & 0.0 & 0.0 & 0.0 & 0.0 & 0.0 & 0.0 & 0.0 & 0.0 & 0.0 \\
\hline 0553 & 0.0 & 0.0 & 0.0 & 0.0 & 0.0 & 0.0 & 0.0 & 0.0 & 0.0 & 0.0 & 0.0 & 0.0 & 0.0 \\
\hline 0622 & 0.0 & 0.0 & 0.0 & 0.0 & 0.0 & 0.0 & 0.0 & 0.0 & 0.0 & 0.0 & 0.0 & 0.0 & 0.0 \\
\hline 0776 & 0.0 & 0.0 & 0.0 & 0.0 & 0.0 & 0.0 & 0.0 & 0.0 & 0.0 & 0.0 & 0.0 & 0.0 & 0.0 \\
\hline 0929 & 11.6 & 0.1 & 0.0 & 0.0 & 0.0 & 0.0 & 0.0 & 0.0 & 0.0 & 0.0 & 0.0 & 0.0 & 0.0 \\
\hline 0982 & 0.0 & 0.0 & 0.0 & 0.0 & 0.0 & 0.0 & 0.0 & 0.0 & 0.0 & 0.0 & 0.0 & 0.0 & 0.0 \\
\hline 0993 & 0.0 & 0.0 & 0.0 & 0.0 & 0.0 & 0.0 & 0.0 & 0.0 & 0.0 & 0.0 & 0.0 & 0.0 & 0.0 \\
\hline 1061 & 0.0 & 0.0 & 0.0 & 0.0 & 0.0 & 0.0 & 0.0 & 0.0 & 0.0 & 0.0 & 0.0 & 0.0 & 0.0 \\
\hline 1065 & 0.0 & 0.0 & 0.0 & 0.0 & 0.0 & 0.0 & 0.0 & 0.0 & 0.0 & 0.0 & 0.0 & 0.0 & 0.0 \\
\hline 1107 & 0.0 & 0.0 & 0.0 & 0.0 & 0.0 & 0.0 & 0.0 & 0.0 & 0.0 & 0.0 & 0.0 & 0.0 & 0.0 \\
\hline 1108 & 76.1 & 39.6 & 19.6 & 9.3 & 4.2 & 2.0 & 0.9 & 0.4 & 0.1 & 0.1 & 0.0 & 0.0 & 0.0 \\
\hline 1130 & 0.0 & 0.0 & 0.0 & 0.0 & 0.0 & 0.0 & 0.0 & 0.0 & 0.0 & 0.0 & 0.0 & 0.0 & 0.0 \\
\hline 1162 & 0.0 & 0.0 & 0.0 & 0.0 & 0.0 & 0.0 & 0.0 & 0.0 & 0.0 & 0.0 & 0.0 & 0.0 & 0.0 \\
\hline 1369 & 0.0 & 0.0 & 0.0 & 0.0 & 0.0 & 0.0 & 0.0 & 0.0 & 0.0 & 0.0 & 0.0 & 0.0 & 0.0 \\
\hline 1381 & 9.6 & 1.0 & 0.1 & 0.0 & 0.0 & 0.0 & 0.0 & 0.0 & 0.0 & 0.0 & 0.0 & 0.0 & 0.0 \\
\hline 1391 & 0.2 & 0.1 & 0.1 & 0.0 & 0.0 & 0.0 & 0.0 & 0.0 & 0.0 & 0.0 & 0.0 & 0.0 & 0.0 \\
\hline 1433 & 0.0 & 0.0 & 0.0 & 0.0 & 0.0 & 0.0 & 0.0 & 0.0 & 0.0 & 0.0 & 0.0 & 0.0 & 0.0 \\
\hline
\end{tabular}

Note. The ruin probability (\%) was estimated for each line of business from the 100,000 Monte Carlo simulations of the Cramér-Lundberg risk process, for different solvency capital levels, with an excess of loss reinsurance. ${ }^{(1)}$ In BRL thousands. Source: developed by the authors, based on the simulations' outcomes.

From Table 8 , it is possible to observe that the LoB 0196, which previously presented ruin probabilities close to $100 \%$, now, even without initial reserve, proves to be close to zero. This fact happens because there is only one observation in its real claims history whose underwriting result unbalances the portfolio. Thus, during the simulation processes, only one or more claims of such severity are sufficient to bankrupt the entity. Therefore, when the insurer's maximum loss is limited to the established priority amount (in this case, BRL 10 million), it is verified that the retained premiums are sufficient to maintain solvency during the risk process development. LoB 1108, 1381, and 1391 also showed significant reductions in their ruin probabilities estimates, in addition to showing extreme sensitivity to initial reserves variations.

As demonstrated in Table 4, there seems to be evidence that LoB 0520 and 0531 have some kind of cross-subsidy. This phenomenon can occur as a result of the products structuring, considering that the coverage of Passengers' Personal Accident (0520) and Vehicle 
Insurance - Hull (0531) are usually offered together in the basic coverage of insurance's policies. In addition, there is legal support (Paragraph 8 of Article 2 of Annex XXVII of CNSP Resolution No. 321/2015) that allows insurers to develop aggregate actuarial methodologies for pricing and claims reserve assessment, as long as the entities are able to demonstrate, through technical basis, some similarity criterion between the grouped businesses (risk factors homogeneity).

Therefore, the LoB 0520 's ruin probability of $3.0 \%$ for a high solvency capital (BRL 6,000,000.00), in fact, would be overestimated, because the line 0531 's excess premium (with expected ruin of $0 \%$ since BRL 0.00 of solvency capital) would help maintain the portfolio balance.

Furthermore, it is important to stress that the nonproportional reinsurance effectiveness is directly associated with a correct priority choice. In the case of a wrong definition, the retained premium will be reduced due to the transfer to the reinsurer of a total premium portion. On the other hand, the incurred claims will not have reinsurance recoveries, since their individual severities do not reach the contractual priority. Thus, the objective of shielding the company's results is not achieved. On the contrary: the business' exposure to a possible insolvency scenario increases, a reality that might not have occurred without the reinsurance implementation.

Figure 2 shows, as an example, the LoB 1381. Figure 2 exemplifies two important conclusions: (a) ruin probability exponential decay shape, considering consecutive increases in solvency capital; and (b) that the adoption of an appropriate reinsurance contract according to the line of business' characteristics allows the ruin estimates curves to be shifted, in view of the reduction on the initial ruin probability from $80 \%$ to $10 \%$.

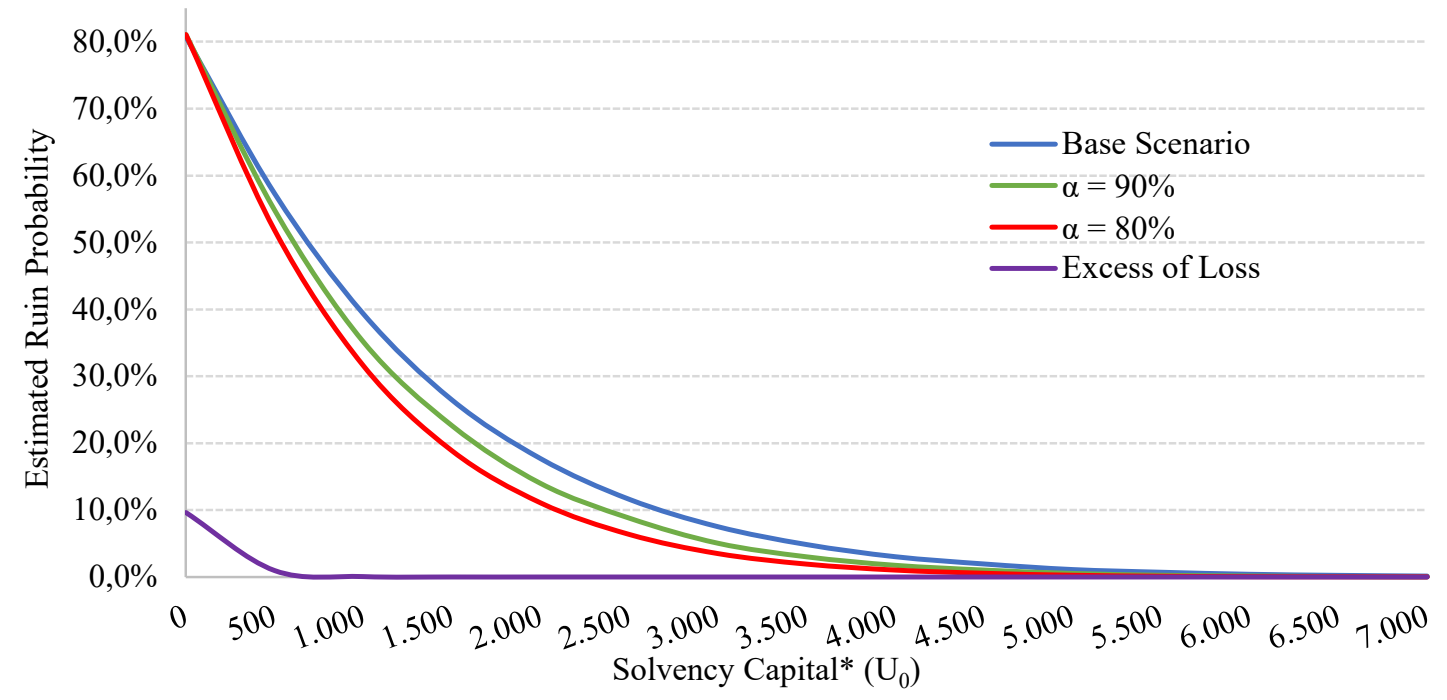

Figure 2. Estimated ruin probability — scenarios comparison for LoB 1381.

* The solvency capital values are expressed in BRL thousands. Source: developed by the authors.

\section{FINAL COMMENTS}

In this paper, we sought to estimate the ruin probability of an insurance company by incorporating reinsurance treaties, comparing to the base scenario in which the managerial operations of revenues and expenses occur without changes in its random variables. There are only few studies in the literature that have proposed direct applications of the risk process to microdata, incorporating reinsurance structures and understanding their effects on insolvency estimates. As a consequence, it was possible to dimension the solvency capital associated with underwriting risks, as well as to analyze its effects in reducing the ruin probability.

To obtain accurate estimates, the methodology developed here was based on computational resources 
that performed routines via MCM. Thus, the paper was structured in four stages: database extraction and validation, with a history of real claims, followed by the probabilistic distributions adjustment, by Susep's line of business. Then, 10,000 aggregate claim scenarios were simulated for each LoB, aiming to measure the ability to generate reliable observations of real claims. With this, three scenarios of risk processes were varied, in which 100,000 temporal paths were simulated, developed, each one, for 210 years.

Finally, it was possible to observe the exponential decay in the relationship between the ruin probability and increases in the solvency capital, with this sensitivity being intensified through the reinsurance contracts adoption. Furthermore, for the same level of initial reserve, the ruin probability is lower with an XL/R treaty compared to a quota share, if the contractual priority is precisely calibrated. For this reason, it is essential that a thorough and technical analysis be carried out when defining the reinsurance panel, aiming to ensure convergence of expectations regarding

\section{REFERENCES}

Afonso, L. B., Cardoso, R. M. R., Reis, A. D. E. dos, \& Guerreiro, G. R. (2017). Measuring the impact of a bonus-malus system in finite and continuous time ruin probabilities for large portfolios in motor insurance. ASTIN Bulletin, 47(2), 417-435. https://doi.org/10.1017/asb.2017.3

Albrecher, H., \& Haas, S. (2011). Ruin theory with excess of loss reinsurance and reinstatements. Applied Mathematics and Computation, 217(20), 8031-8043. https://doi.org/10.1016/j.amc.2011.02.109

Bareche, A., \& Cherfaoui, M. (2019). Sensitivity of the stability bound for ruin probabilities to claim distributions. Methodology and Computing in Applied Probability, 21(4), 1259-1281. https://doi.org/10.1007/s11009-018-9675-7 reducing both the operation volatility and risk management measures in comparison of the real results observed in the portfolios.

For sake of simplicity, intrinsic factors of an insurance company operation were not considered, such as: investment income, dividend payment, administrative expenses, and accrual accounting, constituting the main limitations of this study. Likewise, credit, operational, and market risks were not addressed. Nevertheless, the importance of this study is reinforced by the advent of the new international accounting standards. IFRS 17, which will replace IFRS 4 and come into force in 2023, will further accentuate the indispensability of measuring solvency capital and other amounts (England, Verrall, \& Wüthrich, 2019; Moro \& Krvavych, 2017). Therefore, internal methodologies should be able to incorporate all risk transfer mechanisms, jointly analyzing gross and net values, in addition to explaining to executives and stakeholders the effects that these tools promote on long-term solvency.
Baumgartner, B., \& Gatto, R. (2010). A bootstrap test for the probability of ruin in the compound poisson risk process. ASTIN Bulletin, 40(1), 241-255. https://doi.org/10.2143/AST.40.1.2049227

Bowers, N. L., Gerber, H. U., Hickman, J. C., Jones, D. A., \& Nesbitt, C. J. (1997). Actuarial mathematics (2nd ed.). Schaumburg, IL: The Society of Actuaries.

Charpentier, A. (2010). Reinsurance, ruin and solvency issues: Some pitfalls [Working Paper hal00463381]. HAL Archives-Ouvertes. Retrieved from https://hal.archives-ouvertes.fr/hal-00463381/document

Chen, Y., \& Yuan, Z. (2017). A revisit to ruin probabilities in the presence of heavy-tailed insurance and financial risks. Insurance: Mathematics and Economics, 73, 75-81. https://doi.org/10.1016/j.insmatheco.2017.01.005 
Cheng,J.,Gao,Y., \&Wang,D.(2016).Ruinprobabilitiesforaperturbed risk model with stochastic premiums and constant interest force. Journal of Inequalities and Applications, 2016(1), 214. https://doi.org/10.1186/s13660-016-1135-8

Cheung, E. C. K., Dai, S., \& Ni, W. (2018). Ruin probabilities in a Sparre Andersen model with dependency structure based on a threshold window. Annals of Actuarial Science, 12(2), 269-295. https://doi.org/10.1017/S1748499517000215

Constantinescu, C. D., Kozubowski, T. J., \& Qian, H. H. (2019). Probability of ruin in discrete insurance risk model with dependent Pareto claims. Dependence Modeling, 7(1), 215-233. https://doi.org/10.1515/demo-2019-0011

Coulibaly, I., \& Lefèvre, C. (2008). On a simple quasi-Monte Carlo approach for classical ultimate ruin probabilities. Insurance: Mathematics and Economics, 42(3), 935-942. https://doi.org/10.1016/j.insmatheco.2007.10.008

Deelstra, G., \&Plantin,G. (2014). Risktheoryandreinsurance.London: Springer. https://doi.org/10.1007/978-1-4471-5568-3

Dickson, D. C. M., \& Qazvini, M. (2016). Gerber-Shiu analysis of a risk model with capital injections. European Actuarial Journal, 6(2), 409-440. https://doi.org/10.1007/s13385-016-0131-1

Dong, Y., \& Wang, D. (2018). Uniform asymptotics for ruin probabilities in a two-dimensional nonstandard renewal risk model with stochastic returns. Journal of Inequalities and Applications, 2018(1), 319. https://doi.org/10.1186/s13660-018-1913-6

England, P. D., Verrall, R. J., \& Wüthrich, M. V. (2019). On the lifetime and one-year views of reserve risk, with application to IFRS 17 and Solvency II risk margins. Insurance: Mathematics and Economics, 85, 74-88. https://doi.org/10.1016/j.insmatheco.2018.12.002

Eryilmaz, S., \& Gebizlioglu, O. L. (2017). Computing finite time non-ruin probability and some joint distributions in discrete time risk model with exchangeable claim occurrences. Journal of Computational and Applied Mathematics, 313, 235-242. https://doi.org/10.1016/j.cam.2016.09.025

Gatto, R. (2020). The stability of the probability of ruin. Stochastic Models, 36(1), 112-133. https://doi.org/10.1080/15326349.2019.1695135

Gatto, R., \& Mosimann, M. (2012). Four approaches to compute the probability of ruin in the compound Poisson risk process with diffusion. Mathematical and Computer Modelling, 55(3-4), 1169-1185. https://doi.org/10.1016/j.mcm.2011.09.041

Lefèvre, C., Trufin, J., \& Zuyderhoff, P. (2017). Some comparison results for finite-time ruin probabilities in the classical risk model. Insurance: Mathematics and Economics, 77, 143149. https://doi.org/10.1016/j.insmatheco.2017.09.004
Lemos, S. R. R. (2008). Probabilidade da ruina no mercado de seguros: Fundamentos teóricos e alguns resultados de simulação (Master thesis). Universidade Federal de Pernambuco, Recife, PE, Brazil Retrieved from https://repositorio.ufpe.br/handle/123456789/6171

Melo, E. F. L. de. (2008). Uma aplicação de cópulas de Lévy na agregação de processos multivariados de ruína. Revista Brasileira de Risco e Seguro, 4(7), 47-64. Retrieved from http://www.rbrs.com.br/arquivos/RBRS7-3\%20 Eduardo\%20Fraga.pdf

Mikosch, T., \& Samorodnitsky, G. (2000). Ruin probability with claims modeled by a stationary ergodic stable process. Annals of Probability, 28(4), 1814-1851. https://doi.org/10.1214/aop/1019160509

Moro, E. D., \& Krvavych, Y. (2017). Probability of sufficiency of Solvency II reserve risk margins: Practical approximations. ASTIN Bulletin, 47(3), 737-785. https://doi.org/10.1017/asb.2017.12

Ramsden, L., \& Papaioannou, A. D. (2019). Ruin probabilities under capital constraints. Insurance: Mathematics and Economics, 88, 273-282. https://doi.org/10.1016/j.insmatheco.2018.11.002

Superintendência de Seguros Privados. (2018). 6o relatório de análise e acompanhamento dos mercados supervisionados. SUSEP. Rio de Janeiro, RJ, Brazil. Retrieved from http:// www.susep.gov.br/menuestatistica/SES/6b0\%20Relat Acomp Mercado 2018.pdf

Tamturk, M., \& Utev, S. (2018). Ruin probability via quantum mechanics approach. Insurance: Mathematics and Economics, 79, 69-74. https://doi.org/10.1016/j.insmatheco.2017.12.009

Touazi, A., Benouaret, Z., Aissani, D., \& Adjabi, S. (2017). Nonparametric estimation of the claim amount in the strong stability analysis of the classical risk model. Insurance: Mathematics and Economics, 74, 78-83. https://doi.org/10.1016/j.insmatheco.2017.02.007

Vidmar, M. (2018). Ruin under stochastic dependence between premium and claim arrivals. Scandinavian Actuarial Journal, 2018(6), 505-513. https://doi.org/10.1080/03461238.2017.1391114

Wüthrich, M. V. (2015). From ruin theory to solvency in non-life insurance. Scandinavian Actuarial Journal, 2015(6), 516526. https://doi.org/10.1080/03461238.2013.858401 


\section{Authorship}

\section{Jorge Wilson Euphasio Junior}

Universidade de São Paulo, Faculdade de Economia, Administração, Contabilidade e Atuária

Av. Luciano Gualberto, no 908, Butantã, 05508-010, São Paulo, SP, Brazil.

E-mail address: jorgeeuphasio@gmail.com

(1) https://orcid.org/0000-0003-3112-2281

\section{João Vinícius França Carvalho*}

Universidade de São Paulo, Faculdade de Economia, Administração, Contabilidade e Atuária

Av. Luciano Gualberto, no 908, Butantã, 05508-010, São Paulo, SP, Brazil.

E-mail address: jvfcarvalho@usp.br

(1) https://orcid.org/0000-0002-1076-662X

* Corresponding Author

\section{Funding}

There are no funders to report for this article.

\section{Conflict of Interests}

The authors have stated that there is no conflict of interest.

\section{lagiarism Check}

The RAC maintains the practice of submitting all documents approved for publication to the plagiarism check, using specific tools, e.g.: iThenticate.

\section{Copyrights}

RAC owns the copyright to this content.

\section{Authors' Contributions}

$\mathbf{1}^{\text {st }}$ author: data curation (equal); formal analysis (equal); investigation (equal); software (equal); validation (equal); visualization (equal); writing-original draft (equal); writingreview \& editing (equal).

$2^{\text {nd }}$ author: conceptualization (lead); data curation (equal); formal analysis (equal); investigation (equal); methodology (equal); project administration (lead); software (equal); supervision (lead); validation (equal); visualization (equal); writing-original draft (equal); writing-review \& editing (equal).

\section{Peer Review Method}

This content was evaluated using the double-blind peer review process. The disclosure of the reviewers' information on the first page, as well as the Peer Review Report, is made only after concluding the evaluation process, and with the voluntary consent of the respective reviewers and authors.

\section{Data Availability}

The authors chose not to share their database, and claim that they do so in view of the fact that one of the authors signed an information confidentiality agreement with the entity that kindly provided the data only for the development of the research. This duly signed public document was sent to RAC as a formal justification for not sharing data. The authors affirm to support the Open Science policy promoted by RAC in everything that is within the legal reach.

RAC encourages data sharing but, in compliance with ethical principles, it does not demand the disclosure of any means of identifying research subjects, preserving the privacy of research subjects. The practice of open data is to enable the reproducibility of results, and to ensure the unrestricted transparency of the results of the published research, without requiring the identity of research subjects. 